\title{
RECONSTRUÇÃO DE COURO CABELUDO APÓS MORDEDURA CANINA
}

\author{
SCALP RECONSTRUCTION AFTER DOG BITE
}

\author{
Jefferson Lessa Soares de Macedo, TCBC-DF ${ }^{1}$ \\ Simone Correa Rosa ${ }^{1}$
}

\begin{abstract}
RESUMO: Objetivo: Avaliar a conduta de reconstrução imediata das mordeduras caninas em couro cabeludo. Método: Foram avaliados prospectivamente 55 pacientes vítimas de mordedura canina na cabeça, atendidos na emergência do Serviço de Cirurgia Plástica, Hospital Regional da Asa Norte (HRAN, Brasília-DF) de janeiro de 1999 a dezembro de 2001. Resultados: Nove (16,4\%) dos 55 pacientes apresentavam lesões extensas de couro cabeludo, dos quais sete eram menores de 10 anos. Nesses nove casos, o tratamento mais utilizado foi a sutura direta (77,8\%), seguido pelo enxerto do couro cabeludo avulsionado em $22,2 \%$ dos casos. Não houve infecção nos casos estudos. Conclusões: $\mathrm{O}$ fechamento primário das lesões em couro cabeludo após mordeduras caninas mostrou-se seguro.
\end{abstract}

Descritores: Mordedura e picadas; Cães; Couro cabeludo; Reconstrução.

\section{INTRODUÇÃO}

As mordeduras caninas são uma importante causa de morbidade e mortalidade no nosso meio ${ }^{1}$. Os ataques frequientes de cães a crianças e adultos têm ocupado as páginas dos jornais quase que diariamente. São um problema de saúde pública, pois além da ameaça à integridade física das pessoas, as mordeduras caninas podem transmitir a raiva e propiciar o surgimento de infecções graves. Esse fato tem mobilizado a opinião pública, os políticos e pessoal da área de saúde para que se façam mudanças na legislação brasileira, campanhas de prevenção e tratamento das vítimas dessas lesões.

As mordeduras representam $0,3 \%$ a $1,1 \%$ dos atendimentos nas emergências dos hospitais ${ }^{2-4}$. Nos anos de 1992 a 1994 nos Estados Unidos, a média anual de atendimentos por mordeduras caninas foi de 333.687 casos, com uma taxa de 12,9 por 10.000 pessoas, sendo que $4 \%$ destes pacientes tiveram tratamento especializado ou internação.
No mesmo período, foram atendidos em média 914 casos novos de mordeduras por cães por dia nos Estados Unidos. As crianças são as principais vítimas. Acredita-se que metade das crianças em alguma fase de suas vidas foram mordidas por cães, e o principal sítio nesta faixa etária é a cabeça. $\mathrm{O}$ custo anual do tratamento das vítimas de mordeduras é de 165 milhões de dólares. A dor e o sofrimento são incalculáveis, principalmente quando se trata de crianças ${ }^{4}$.

No Brasil, no ano de 2000, foram atendidas 418.360 pessoas vítimas de mordeduras caninas. Além disto, foram notificados 23 casos de raiva humana, cujo animal agressor foi o cão ${ }^{5}$.

Atualmente, nos casos de mordeduras na face, é aceito e seguro o fechamento direto das lesões ${ }^{2,6-9}$. Entretanto, não existe estudo específico do fechamento primário das mordeduras em couro cabeludo. O objetivo deste trabalho foi avaliar a conduta de reconstrução imediata das mordeduras caninas em couro cabeludo.

1. Cirurgião Plástico, Serviço de Cirurgia Plástica, Hospital Regional da Asa Norte (HRAN), Secretaria de Saúde do Distrito Federal, Brasília-DF. 


\section{MÉTODO}

O estudo é do tipo série prospectiva de casos e compreendeu 55 pacientes vítimas de mordeduras caninas que foram atendidos inicialmente na emergência do Serviço de Cirurgia Plástica do Hospital Regional da Asa Norte (Brasília-DF), no período de janeiro de 1999 a dezembro de 2001.

Os dados foram colhidos através de questionário, de forma prospectiva. As variáveis analisadas foram: idade, sexo, procedência, intervalo de tempo da agressão ao atendimento hospitalar, agente agressor, local dos ferimentos, características das lesões e tratamento.

A conduta nos casos de mordedura de couro cabeludo e face foi de irrigação copiosa da ferida, e limpeza com solução degermante de polivinilpirrolidona (P.V.P.I.) e soro fisiológico. O fechamento primário no dia do atendimento foi feito através de sutura direta, retalho local ou enxerto. Não houve limite de horas ou dias, entre o momento da agressão e o procedimento cirúrgico, ou seja, no momento em que o paciente chegava à emergência do hospital era realizado tal procedimento, independente da hora ou dia da agressão. Somente os tecidos desvitalizados foram desbridados e não havia sinal de infecção da ferida no momento do fechamento.

A anestesia realizada foi a local ou geral, dependendo da extensão dos ferimentos e da idade do paciente. Foi realizada profilaxia do tétano e da raiva conforme o caso, e antibióticos por uma semana (Cefalexina $500 \mathrm{mg}$ VO 6/6h ou conforme o peso da criança). As suturas foram retiradas entre o sétimo e o décimo quinto dias pós-operatório.

\section{RESULTADOS}

Dos 55 pacientes, o couro cabeludo foi o sítio principal das lesões em nove $(16,4 \%)$ (Tabela 1). Entre estes, a média de idade foi de 10 anos (variação de 3 a 31 anos), sendo que $77,8 \%$ eram menores de 10 anos. A maioria dos pacientes era do sexo feminino $(55,5 \%)$ e todos os pacientes eram procedentes do Distrito Federal. Todos os casos foram atendidos no Serviço de Cirurgia Plástica do Hospital Regional da Asa Norte dentro das primeiras seis horas após o acidente.

Quanto à gravidade das lesões, todas eram extensas e três $(33,3 \%)$ pacientes apresentavam perda de substância (Figura 1). Um paciente apresenta- va lesões extensas de couro cabeludo associadas a fraturas de osso occipital, temporal esquerdo, malar e seio maxilar esquerdo, tendo sido submetido a tratamento neurocirúrgico e das partes moles. Não houve mortes ou casos de infecção no estudo.

O tipo de tratamento mais comum foi a sutura direta em sete $(77,8 \%$ ) casos (Figuras 1 e 2), seguida por enxerto do couro cabeludo avulsionado em dois casos (Figuras 3 e 4). O tipo de anestesia mais utilizado foi a anestesia geral, em sete casos, por serem crianças com lesões extensas de face e couro cabeludo.

Tabela 1 - Distribuição dos casos de mordeduras caninas na face e couro cabeludo atendidas no Hospital Regional da Asa Norte, Brasília, DF, quanto ao local da lesão.

\begin{tabular}{lcr}
\hline Local da lesão & $\mathbf{N}^{\circ}$ pacientes & \% \\
\hline Lábio & 12 & 21,8 \\
Couro cabeludo & 9 & 16,4 \\
Zigomática & 9 & 16,4 \\
Nariz & 9 & 16,4 \\
Orelha & 7 & 12,7 \\
Pálpebra & 7 & 12,7 \\
Frontal & 2 & 3,6 \\
\hline Total & 55 & 100,0 \\
\hline
\end{tabular}

\section{DISCUSSÃO}

O cão é o agente agressor mais comum nas mordeduras da face e couro cabeludo. As agressões caninas representam $90 \%$ das mordidas por animais que exigem cuidados médicos, matando 10 americanos por ano e, geralmente, são cães da família ou de vizinhos 2,10-14.

De 1979 a 1996, morreram 304 pessoas nos Estados Unidos vítimas de ataques por cães ${ }^{15,16}$. Estima-se que a taxa de atendimento de mordeduras caninas nas emergências americanas seja de 1,3 por 1.000 habitantes, levando a 44.000 lesões faciais por mordeduras caninas anualmente ${ }^{17,18}$. Entretanto, esta taxa está abaixo da realidade, pois apenas $36 \%$ das mordeduras caninas são atendidas nos hospitais ou informadas às autoridades de controle de animais e polícia ${ }^{19}$.

Segundo o CDC de Atlanta, as crianças pagam o maior preço, pois $26 \%$ das mordeduras em 

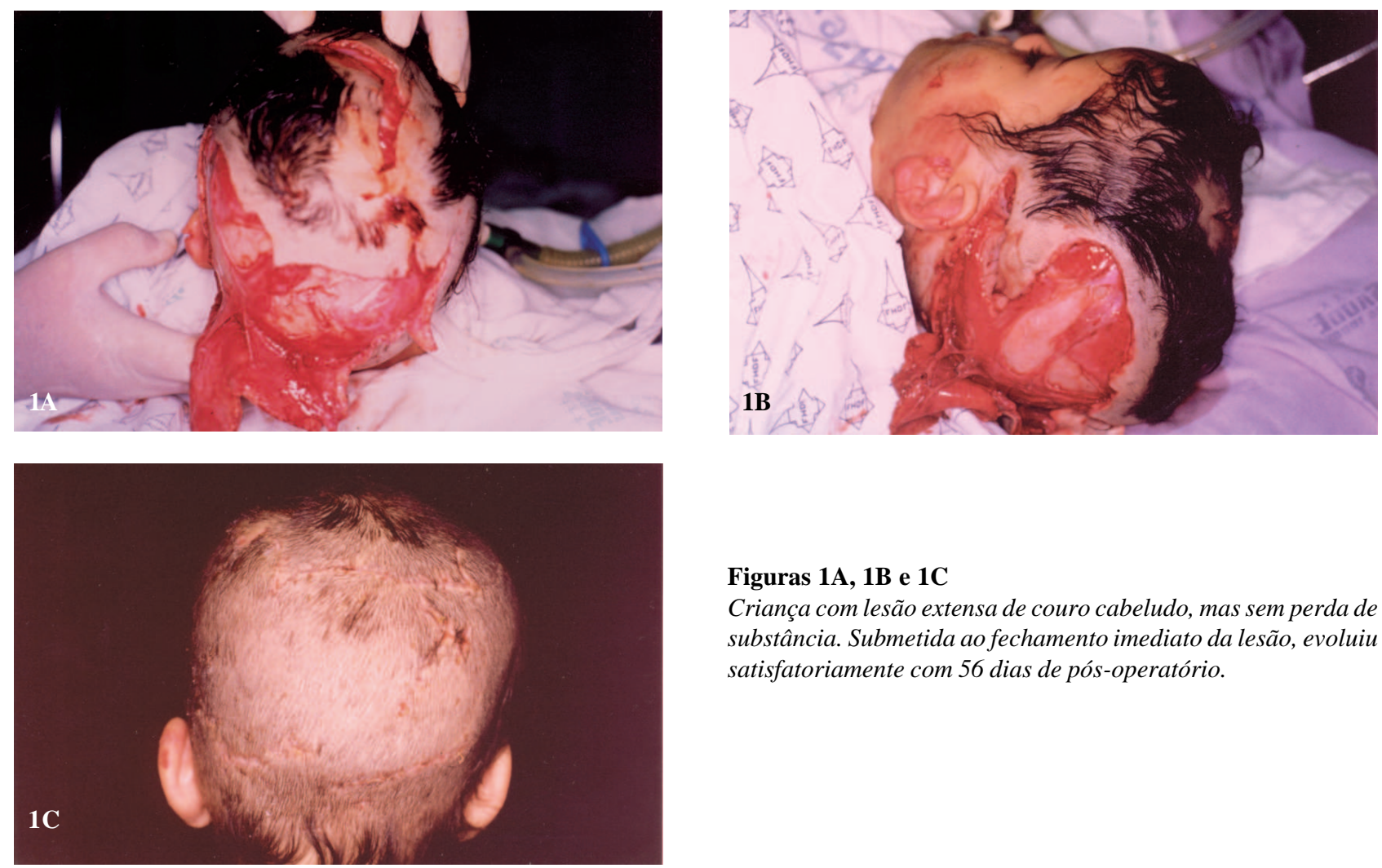

Figuras 1A, 1B e 1C

Criança com lesão extensa de couro cabeludo, mas sem perda de substância. Submetida ao fechamento imediato da lesão, evoluiu satisfatoriamente com 56 dias de pós-operatório.
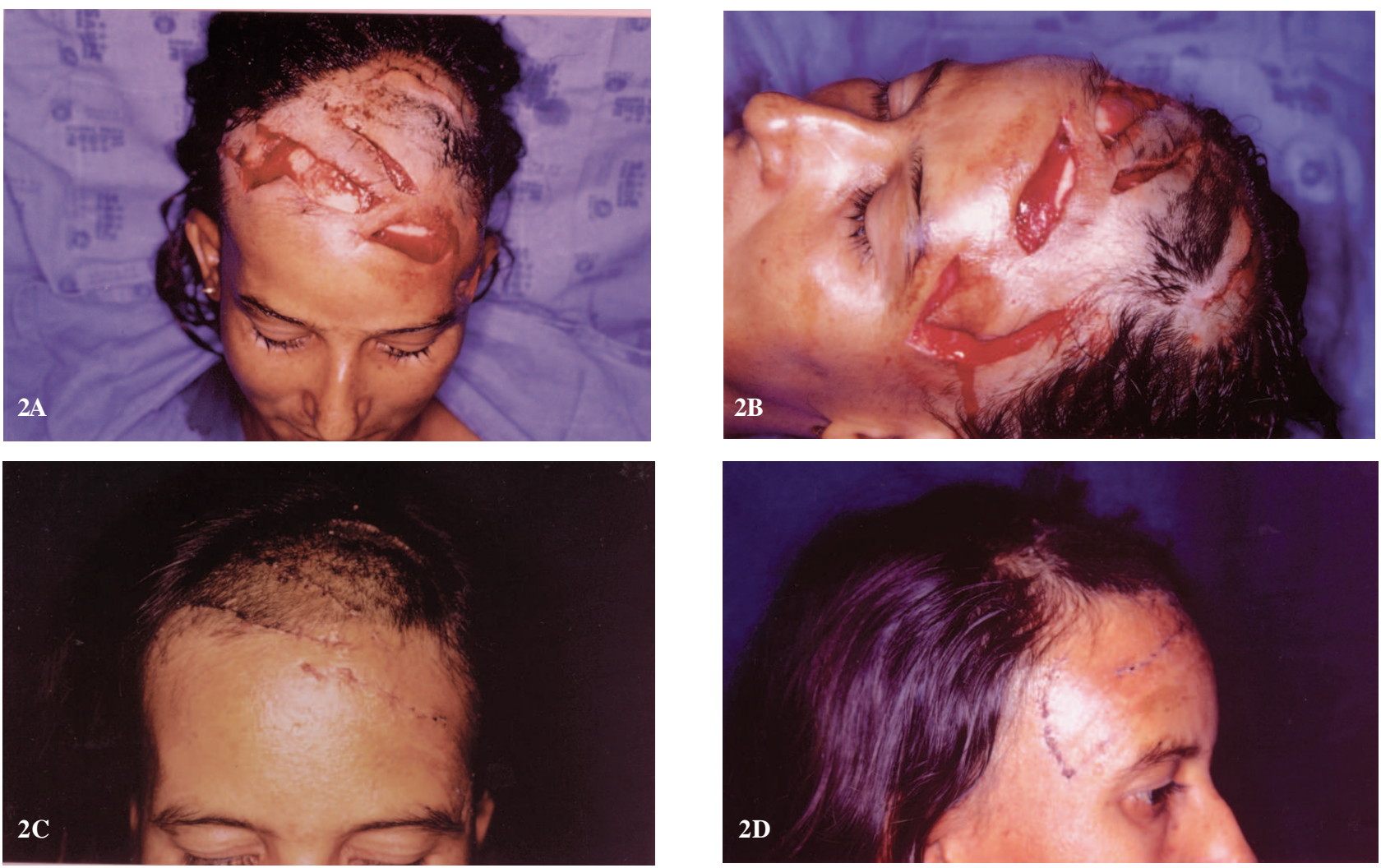

Figuras 2A, 2B, 2C e 2D - Paciente de 31 anos, sem perda de substância, submetida ao fechamento imediato da lesão, evoluiu satisfatoriamente com 22 dias de pós-operatório. 

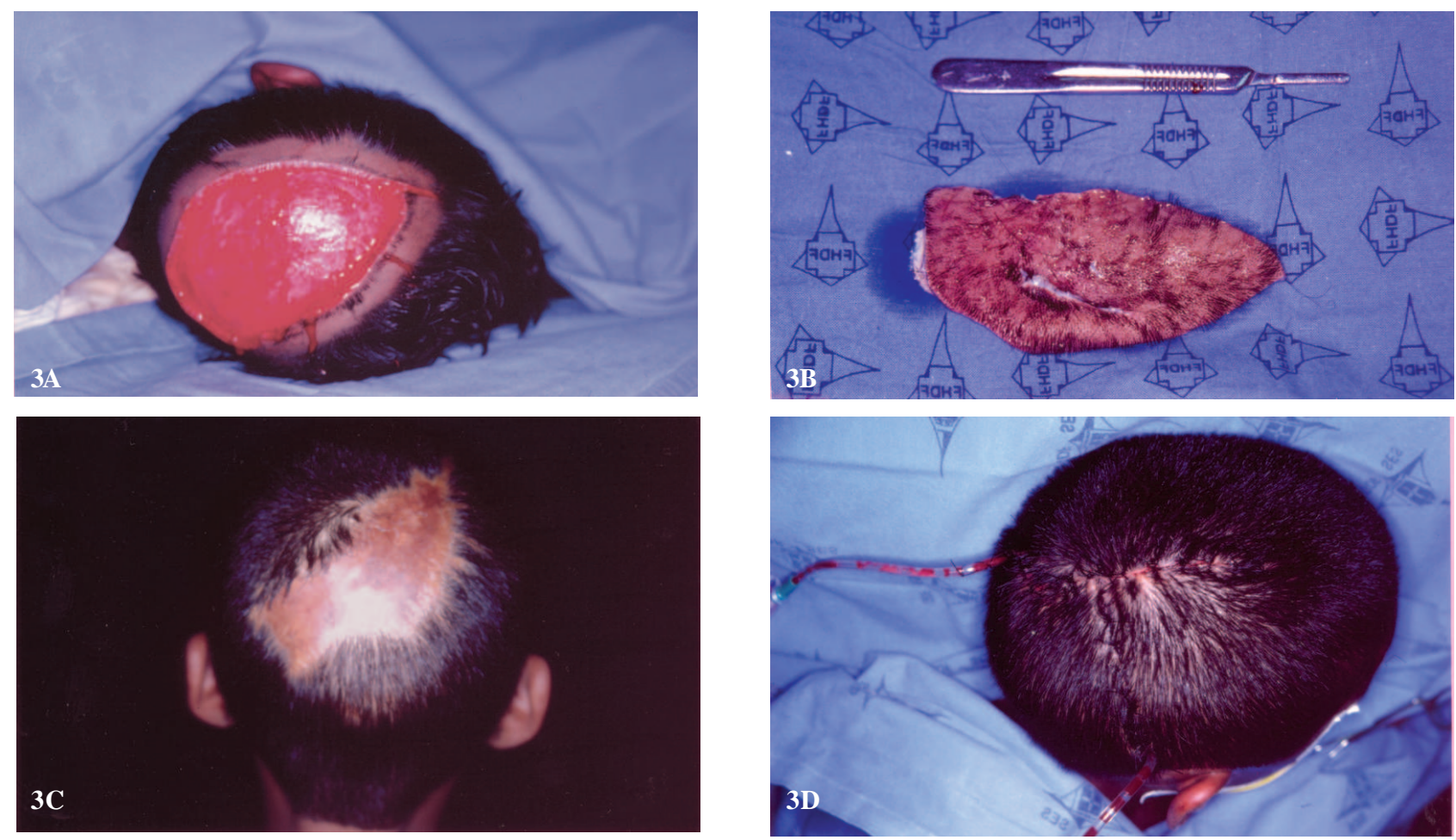

Figuras 3A, 3B, 3C e 3D - Criança de 6 anos, com avulsão parcial do couro cabeludo, submetida a enxertia imediata do segmento avulsionado. Após 6 meses da enxertia, foi submetido a ressecção da área de alopécia e fechamento direto do couro cabeludo.
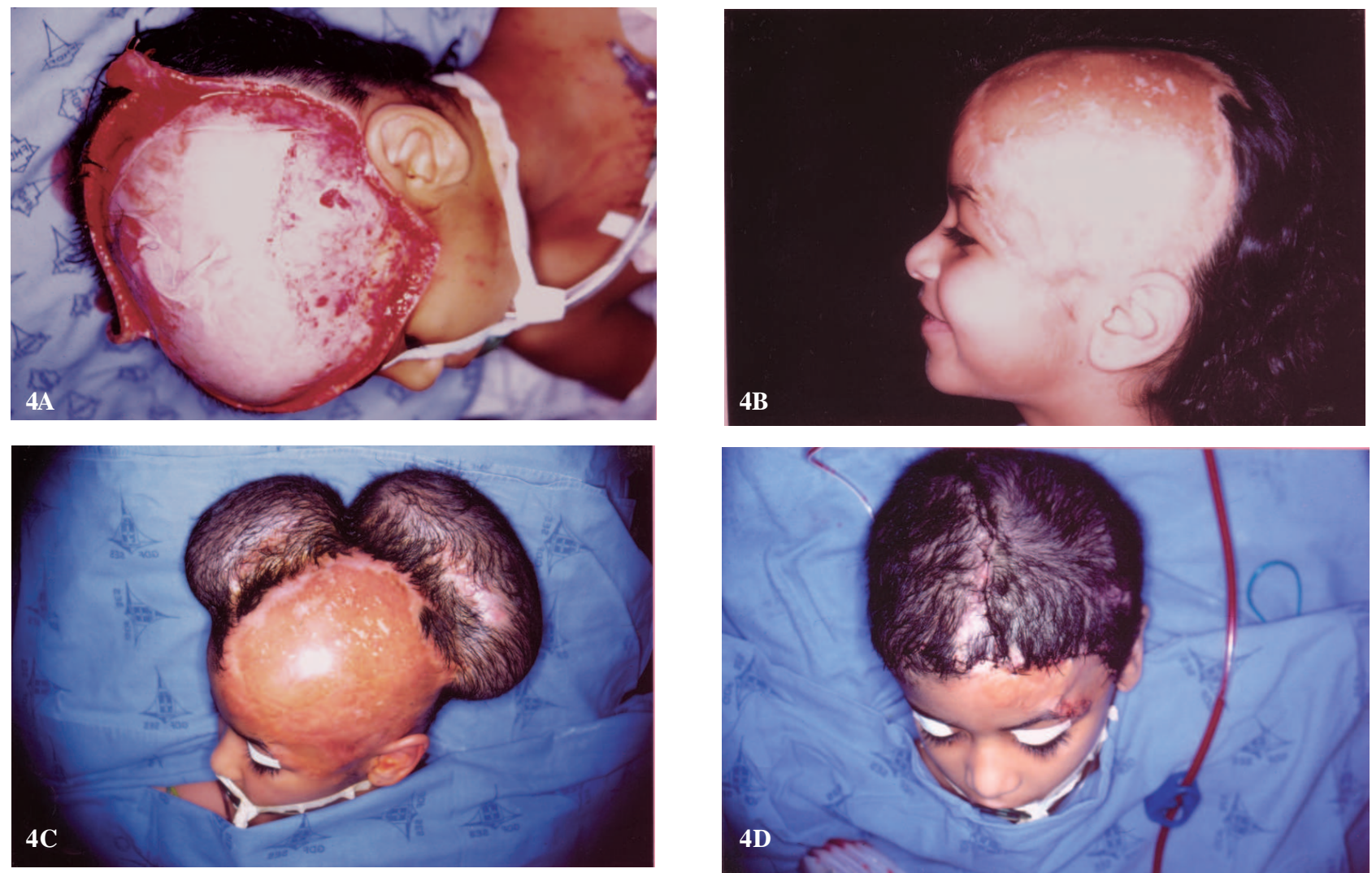

Figuras 4A, 4B, 4C e 4D - Criança de 7 anos, submetida a enxertia imediata do segmento avulsionado. Após 4 meses foi submetida a expansão do couro cabeludo remanescente por 3 meses, e submetida ao avançamento do retalho expandido sobre a área de alopécia. 
crianças necessitam de cuidados médicos, comparado com $12 \%$ em adultos, e as crianças são as principais vítimas fatais dos ataques caninos ${ }^{16}$. Por serem menores, elas sofrem mordeduras na cabeça e tem lesões mais desfigurantes que os adultos. Entre as crianças com menos de 9 anos, $73 \%$ das lesões são na cabeça, enquanto nas outras idades, somente $30 \%$ das lesões ocorrem neste segmento do corpo ${ }^{4}$.

É essencial a realização de um exame clínico completo, associado a uma exploração detalhada da ferida sob anestesia geral conforme o caso. Lesões associadas das vias aéreas, coluna cervical, estruturas vasculares e nervosas, estruturas intracranianas e oculares, e fraturas faciais, principalmente nas crianças, devem ser pesquisadas $18,20,21$. No nosso estudo, havia uma criança com múltiplas fraturas cranianas e da face, que exigiu intervenção neurocirúrgica durante o reparo das lesões na face e couro cabeludo.

O local mais comum dos ataques caninos na cabeça foi o lábio, compatível com os achados de outros autores ${ }^{6,10,13}$. O couro cabeludo ocupou o segundo lugar como sítio das mordeduras caninas, assim com a região zigomática e o nariz.

Nas agressões caninas é obrigatório a profilaxia do tétano e da raiva, pois estas são responsáveis pela transmissão de $85 \%$ dos casos de raiva humana no Brasil ${ }^{5}$.

O uso de antibiótico por cinco a sete dias após mordeduras na cabeça é amplamente aceito na literatura, e o antibiótico de escolha é a amoxacilinalclavulanato ou a cefalexina. O uso da cultura para escolher o antibiótico só é feita em casos em que a infecção está estabelecida, e os germes mais freqüentes são os estreptococos e os estafilococos ${ }^{2,3,22}$.Entretanto, não podemos esquecer a possibilidade de infecção Gram-negativos, como a Pasteurella multocida e anaeróbios Gram-positivos que normalmente estão presentes na flora bacteriana da cavidade oral do cão e podem ser inoculadas, levando à infecção da ferida.

A infecção da ferida não foi observada nesse estudo, mas é a complicação mais comum após mordeduras. A probabilidade de infecção é influenciada por diversos fatores, como: o animal agressor, a localização da ferida, os fatores inerentes ao indivíduo, as características das lesões e o tempo para atendimento ${ }^{23}$.

Atenção deve ser dada à septicemia por Capnocytophaga canimorsus em casos de doen- ça febril após mordeduras caninas ou contato com cães, principalmente em pacientes com esplenectomia prévia ou alcoolismo crônico ${ }^{24}$. Não observamos tais casos no nosso estudo, o que é compatível com a literatura, já que estes casos de infeções sistêmicas graves são mais comuns após mordeduras nas mãos ou dedos, e raramente após mordeduras na cabeça.

O tratamento primário das mordeduras foi realizado através de sutura direta ou enxerto conforme o tipo de ferida e decisão do cirurgião. Sempre que possível foi realizada sutura direta, mas em casos de avulsão de parte do couro cabeludo, procedeu-se ao enxerto do segmento avulsionado (Figuras 3 e 4). Posteriormente, após a integração do enxerto, o cirurgião pode iniciar a expansão do couro cabeludo remanescente para a cobertura da área de alopécia do enxerto (Figura 4).

A sutura primária das lesões, apresenta vantagens sobre o fechamento retardado. Em crianças, por exemplo, as explorações de mordeduras caninas na admissão requerem anestesia geral, assim como o reparo alguns dias depois, ou seja, dois procedimentos anestésicos em uma semana. Além disso, as lesões abertas exigem curativos diários, e altas doses de analgésicos são necessárias durante e após a troca de curativos. Estas desvantagens são evitada pelo reparo cirúrgico imediato, e esta última conduta permite ao cirurgião resolver o problema do dano estético.

O reimplante microcirúrgico do couro cabeludo e de ourtros segmentos avulsionados após mordedura pode ser tentado, com bons resultados estéti$\cos { }^{13,25}$. No nosso estudo, não foi utilizada a reconstrução com retalhos microcirúrgicos.

Completando a conduta terapêutica, é desejável encaminhar a vítima da mordedura para um acompanhamento psicológico. Esses pacientes podem manifestar dificuldades de ajustamento social após o trauma, principalmente quando apresentam lesões desfigurantes ${ }^{26}$.

Estudos anteriores sugerem que o fechamento imediato das mordeduras na face é seguro, até mesmo após várias horas da lesão $2,6,7,8,10,11,18,23$. Nosso trabalho também demonstra que as lesões do couro cabeludo podem ser reparadas primariamente. Com esta conduta alcança-se um melhor resultado estético, com mínimo ou nenhum risco de infecção, diminuindo os procedimentos cirúrgicos posteriores e melhorando a morbidade. 


\begin{abstract}
Background: Evaluation of the management of immediate scalp reconstruction after dog bites. Methods: There were 55 victims of dog bites on the head seen on the emergency room of the Plastic Surgery Unit, Hospital Regional da Asa Norte (HRAN, Brasilia, DF, Brazil) from January, 1999 through December, 2001. Results: Nine (16.4\%) patients had extense injuries on the scalp. From these patients, seven (77.8\%) were less than ten years old. The treatment was suture of the lesion of most cases $(77,8 \%)$. The other cases $(22.2 \%)$ were treated with graft of the scalp. There was no infection on this series of cases. Conclusions: The results indicate that immediate closure of dog bite injuries to the scalp is safe, either by direct suturing or scap grafting.
\end{abstract}

Key Words: Bits and Stings; Dogs; Scalp; Reconstruction.

\section{REFERÊNCIAS}

1. Del Ciampo LA, Ricco RG, Almeida CAN, et al. - Acidentes de mordeduras de cães na infância. Rev Saúde Pública, 2000, 34(4):411-412.

2. Ruskin JD, Laney TJ, Wendt SV, et al. - Treatment of mammalian bite wounds of the maxillofacial region. $\mathrm{J}$ Oral Maxillofac Surg, 1993, 51(2):174-176.

3. Goldstein EJ, Richwald GA - Human and animal bite wounds. Am Fam Physician, 1987, 36(1):101-109.

4. Weiss HB, Friedman DI, Coben JH - Incidence of dog bite injuries treated in emergency departments. JAMA, 1998, 279(1):51-53.

5. Ministério da Saúde. Fundação Nacional de Saúde. Guia de vigilância epidemiológica. $6^{\text {a }}$ edição, capítulo de raiva, 2000.

6. Donkor P, Bankas DO - A study of primary closure of human bite injuries to the face. J Oral Maxillofac Surg, 1997, 55(5):479-482.

7. Mcheik JN, Vergnes P, Bondonny JM - Treatment of facial dog injuries in children: a retrospective study. J Pediatr Surg, 2000, 35(4):580-583.

8. Javaid M, Feldberg L, Gipson M - Primary repair of dog bites to the face: 40 cases. J R Soc Méd, 1998, 91(8):414-416.

9. Fleisher GR - The management of bite wounds. N Engl J Med, 1999, 340(2): 138-140.

10. Palmer J, Rees M - Dog bites of the face: a 15 year review. Br J Plast Surg, 1983, 36(3):315-318.

11. Mondragón Dominguez M, Lozano Tellez S, Peredo Resk GH, et al. - Heridas por mordedura de perro: tratamiento de 40 pacientes. Acta Pediátr Méx, 1997, 18(3):120-123.

12. Rohrich RJ - Man's best friend revisited: who's watching the children? Plast Reconstr Surg, 1999, 103(7):2067-2068

13. Wolff KD - Management of animal bite injuries of the face: experience with 94 patients. J Oral Maxillofac Surg, 1998, 56(7):838-844
14. Avner JR, Baker MD - Dog bites in urban children. Pediatrics, 1991, 88(1):55-57.

15. Sacks JJ, Sattin RW, Bonzo SE - Dog bite-related fatalities from 1979 through 1988. JAMA, 1989, 262(11):1489-1492.

16. Sacks JJ, Lockwood R, Hornreich J, et al. - Fatal dog attacks, 1989-1994. Pediatrics, 1996, 97(6 pt 1): 891-895.

17. Dog-bite-related fatalities: United States, 1995-1996. MMWR Morb Mortal Wkly Rep, 1997, 46(21): 463-467

18. Morgan JP, Haug RH, Murphy MT - Management of facial dog bite injuries. J Oral Maxillofac Surg, 1995, 53(4):435-441.

19. Chang YF, McMahon JE, Hennon DL, et al. - Dog bite incidence in the city of Pittsburgh: a capture-recapture approach. Am J Public Health, 1997, 87(10): 1703-1705

20. Tu AH, Girotto JA, Singh N, et al. - Facial fractures from dog bite injuries. Plast Reconstr Surg, 2002, 109(4):1259-1265.

21. Varela JE, Dolich MO, Fernandez LA, Kane A, et al. Combined carotid artery injury and laryngeal fracture secondary to dog bite: case report. Am Surg, 2000, 66(11):1016-1019.

22. Stucker FJ, Shaw GY, Boyd S, et al. - Management of animal and human bites in the head and neck. Arch Otolaryngol Head Neck Surg, 1990, 116(7):789793.

23. Macedo JLS, Silva AA - Fechamento primário das mordeduras na face. Rev Col Bras Cir, 2000, 27(5): 316-320.

24. Pers C, Gahrn-Hansen B, Frederiksen W Capnocytophaga canimorsus septicemia in Denmark, 1982-1995: review of 39 cases. Clin Infect Dis, 1996, 23(1):71-75.

25. Walton RL, Beahm EK, Brown RE, et al. - Microsurgical replantation of the lip: a multi-institutional experience. Plast Reconstr Surg, 1998,102(2):358-368. 
26. Rusch MD, Grunert BK, Sanger JR, et al. Psychological adjustment in children after traumatic disfiguring injuries: a 12-month follow-up. Plast Reconstr Surg, 2000, 106(7):1451-1460.
Endereço para correspondência::

Dr. Jefferson Lessa Soares de Macedo SQS 213 Bloco "H" Apto 104

Asa Sul. Brasília, DF - CEP: 70292-080

Tel. (FAX): 327-8415 